\title{
BIM virtual construction technology applied in project management
}

\author{
YafeiLiu*, SonganLiu \\ School of Resource Exploration \& Civil Engineering, The Engineering \& Technology College of \\ Chengdu University of Technology , Leshan,Sichuan, 614000, China \\ Email:15884379310@163.com
}

\begin{abstract}
Keywords:Building information modeling; virtual construction technology; project management; processes; implementation of key points
\end{abstract}

\begin{abstract}
With the advent of the global information technology, China's major industries have also entered the information process, but the construction industry relative to other industries, manufacturing industry, electronic industry and so is still relatively backward, and the degree of information that most directly affect the construction phase. At present the use of management and production levels of traditional construction mode construction industry are relatively low, the urgent need to use the information as the representative of modern scientific and technological means to change the status quo, so that the rapid development of building information modeling in the construction industry. BIM-based virtual construction technology for construction enterprise innovation and development in the new situation find a breakthrough. Combined with years of virtual construction application practice, introduced based onBIM virtual construction technology management ideas, put forward the characteristics and application of virtual construction, and highlights the virtual construction technology to process and project management operation points.
\end{abstract}

\section{Introduction}

As China's economic take-off, the current value of the scale of the construction industry for more than ten trillion, but with the slowdown in fixed asset investment growth, an increase in construction output fell a reality, construction demand exceeds supply situation become more intensified [1, 2]. How to create a new situation in the survival and development of the competition is the biggest challenge facing the new era of construction enterprises [3]. BIM-based virtual construction technology of the innovation developed in the new situation to find a breakthrough. With the rapid economic development, the city's high-rise buildings mushrooming, the construction industry has become the main industry of the national economy [4]. However, the pace of development of the construction industry has become increasingly unable to meet the people's demand for the building, people need only meet the functional requirements of the building but also to meet the visual needs, so a variety of complex building respected by people, but for today's low efficiency, management not fine, low degree of information integration construction project construction side is undoubtedly a huge challenge $[5,6]$.

Since the mid-20th century, computer technology has gradually penetrated the construction industry, but relative to the level of computer application in other areas, the construction sector is still relatively low [7]. Traditional CAD technology is essentially to show just a simple geometric point, line, surface, such as one kind of drawing tools architectural design, there is no direct link between the individual and mutual constraints of building elements of which it is drawn, and the resulting data in two-dimensional graphics in a subsequent rarely be used, so that the construction side can not fully utilize CAD drawing to guide the construction, in the vast majority of the construction process can only rely on their own three-dimensional imagination and experience [8].

This article appeared in the building for the complex construction process issue, the introduction of BIM technology to effectively solve the complete 3D model of information through a variety of BIM software and to build the 4D BIM model based on the construction of a virtual member, and finally inter-system collision detection.At present the use of management and production levels of 
traditional construction mode construction industry are relatively low, the urgent need to use the information as the representative of modern scientific and technological means to change the status quo, so that the rapid development of building information modeling in the construction industry.

\section{BIM concept}

BIM technology is object-oriented, three-dimensional geometric model, it contains additional information and support for open standards, these four key characteristics. Object-oriented, ie an object-oriented representation of the building, so the building has become a collection of a large number of physical objects; three-dimensional geometric model, namely the use of three-dimensional geometric model of the object as a truthful representation, and reflects the relationship between objects; contains additional information, that contains additional information in the building information model-based three-dimensional geometry, making all kinds of objects according to the specified statistical information, analysis possible; supports open standards that support open standards by building information exchange, so that the whole building life information generated by each phase of the cycle can easily be shared links or in the subsequent stage, avoid duplication of entry information.

Complex projects referred to herein is relative to the average in terms of the project. The complexity of the project management was mainly due to the complexity of the system elements, between complexity and system elements and environmental factors complexity of the structure, mode of action of environmental complexity, specifically shown in Fig. 1. Complexity factors generally refer to the complexity of the process of the project and the level of complexity, organizational relationships, the complexity of the objectives and requirements, project information management complexity of the process and so on.

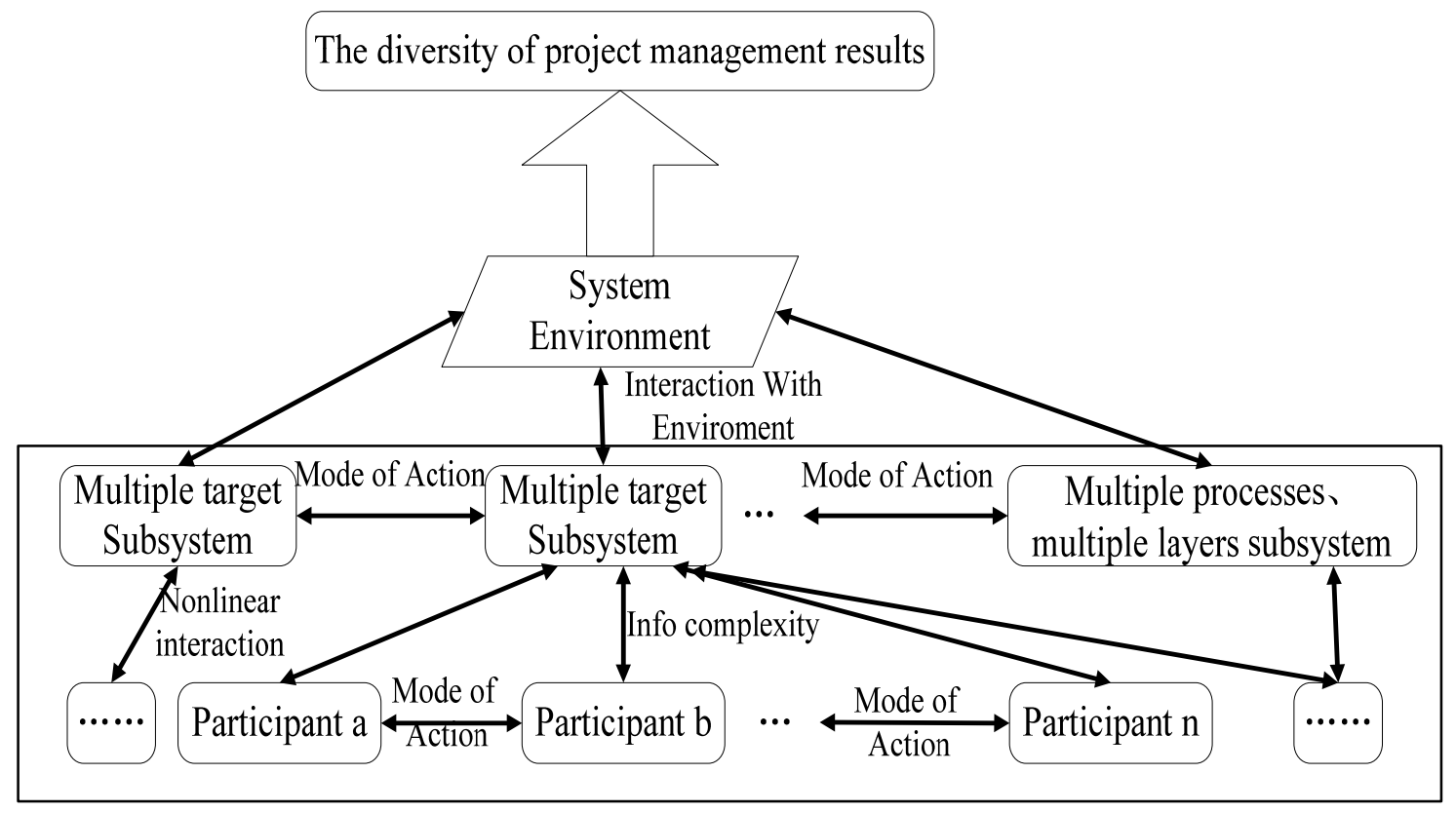

Figure 1. Complex sources of project

Environmental complexity refers primarily to the project location and political environment, legal environment, economic environment, national policies, social and cultural development as well as technological innovation environment, climate and other aspects of the dynamic nature of these dynamics create uncertainty last organizational change system .

\section{Features of virtual construction technology}

BIM in construction projects using virtual construction technology project management, site management company can keep abreast of information, timely and accurate issued a directive to 
reduce the costs of communication, to achieve intensive management, improve work efficiency and management level, effectively saving construction management fees. Headquarters-based management of virtual construction technology was shown in Fig. 2.

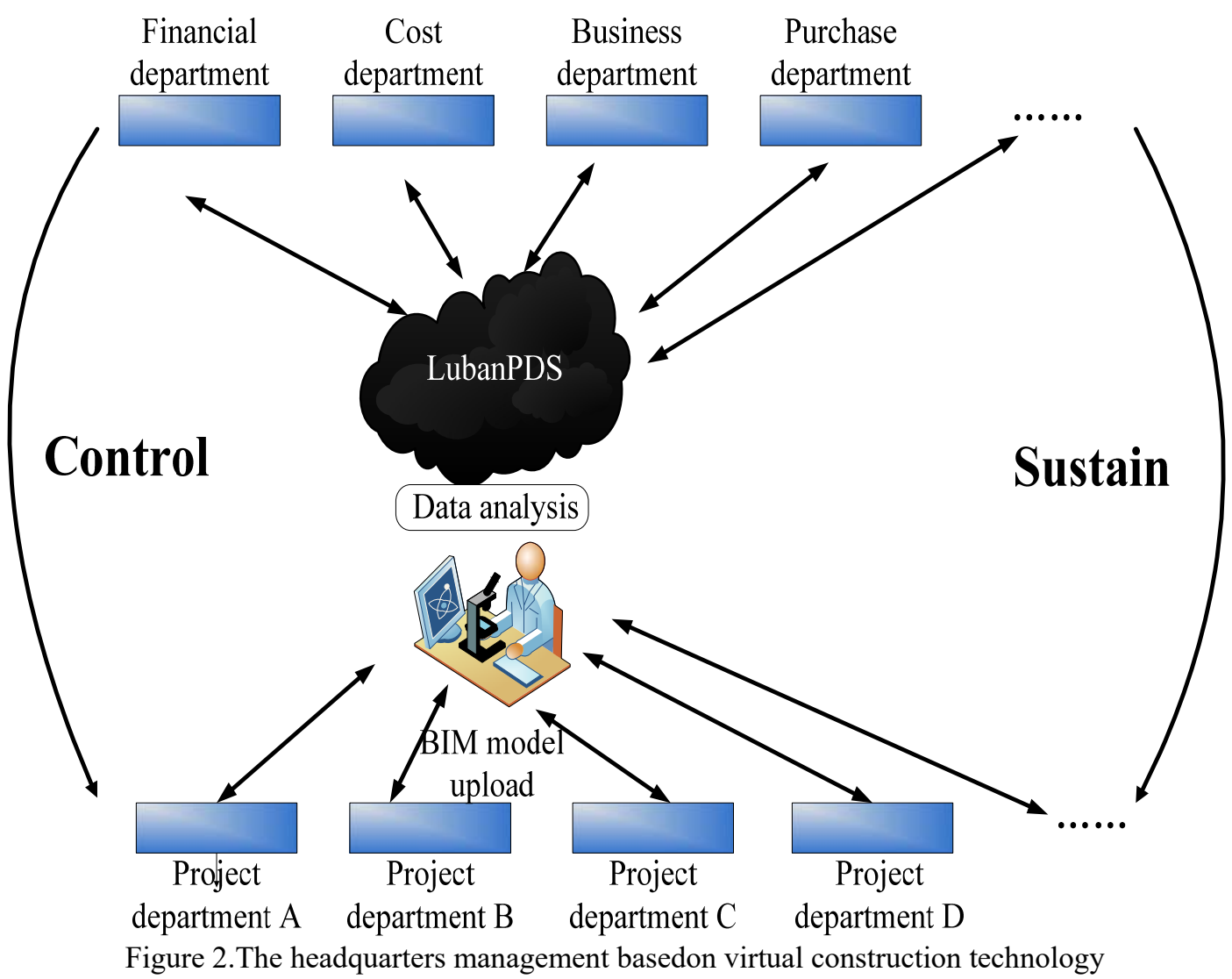

Virtual construction technology utilizes BIM 4D relational database technology, can quickly and accurately obtain engineering data base and split the physical quantity, at any time to provide timely and accurate data to support the development of procurement plans for the project to the limit to provide timely and accurate data to support picking, for the company to project cost control to provide technical support. Traditional construction, it is often difficult to real-time statistics project expenses, party payment is made, the contract should make payments, but also can not change the drawings, according to the image of progress and when, to obtain accurate quantities stipulated in the contract and project cost, virtual construction according to BIM 4D relational database technology with three-dimensional graphics to determine the parameters of regional block diagram bidding, implementation three Operators contrast, monthly output value accounting, monthly progress control, data provide the basis for guiding production.

\section{Results and discussion}

There are two ways fusion model. A method for the direct integration in Revit inside (see Fig. 3), which links through Revit software method to be converted into steel model links IFC file into the civil standard model, but the model can not be changed after such link. Another way is through its integration Navisworks manager software to Revit software model into civil .NWC file, and gradually into the appropriate version or versions Navisworks Manager software, then the IFC standard steel model directly into Navisworks Manager software for the integration model, and a model of fusion collision check and simulate the construction, thus avoiding some of the advance in the actual project can not avoid mistakes. 


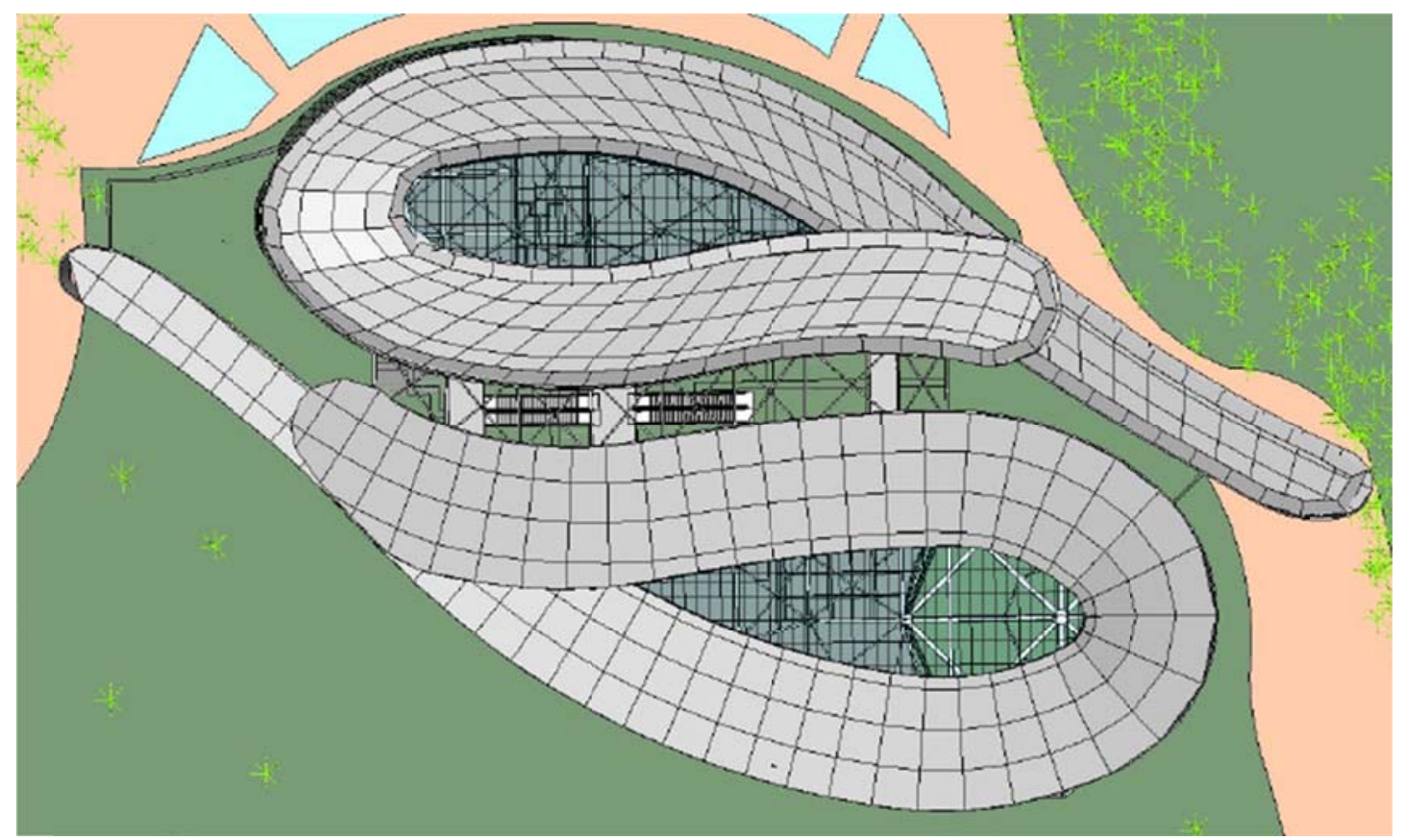

Figure 3.Modeling effects

\section{Summary}

BIM virtual construction technology not only in the early construction were all aspects and detailed program planning, and guide the construction of the entire construction phase of the project in actual construction, a visual tool display parameters of the sub-project, the technological requirements quality flag is set and safety protection facilities, coordination of the professional steps to reduce cross interference phenomena jobs and construction work surface, to prevent the hazards, after construction is completed, you can always reproduce the construction process, as a check, improvement and responsibility retroactive basis.

\section{References}

[1] Raore Soungalo, Li Renfa and Zeng Fanzi, "Evaluating and Improving Wireless Local Area Networks Performance", IJACT: International Journal of Advancements in Computing Technology, vol. 3, no. 2, pp. 156-164, 2011.

[2] 3GPP TS 36.300, "Evolved Universal Terrestrial Radio Access (E-UTRA) and Evolved UTRA (E-UTRA)", Dec. 2008. V8.0.0.

[3] L Tong, G Xu, B Hassibi, and T Kailath. Blind channel estimation based on second-order statistics: a frequency-domain approach. IEEE Trans. Inform. Theory, Vol. 41. Jan 1995. pp:329-334.

[4] Y Zhao, A Huang. A novel channel estimation methods for OFDM mobile communication systems based on pilot signals and transform domain processing [A]. inPro. IEEE 47th Vehicular Technology Conference [C], Phoenix, USA, 1997, pp:2089-2093.

[5] Chung C H, Pasquini L A, Koh C E. Web-based learning management system considerations for higher education[J]. Learning and Performance Quarterly, 2013, 1(4): 24-37.

[6] Masayoshi Ito, Kenneth Yoshioka and Takeshi Saji, "Estimation of Road Surface Conditions Using Wheel Speed Behavior", International Symposium on Advanced Vehicle Control - AVEC'94, No.9438826

[7] Masugi Kaminaga, Genpei Naito, "Vehicle Body Slip Angle Estimation Using an Adaptive Observer", International Symposium on Advanced Vehicle Control-AVEC'98, No.9836635.

[8] Ali Y. Ungoren, Huei Peng, H.E. Tseng, "Experimental Verification of Lateral Speed Estimation Methods", International Symposium on Advanced Vehicle Control-AVEC 2002. 